\title{
UMA ESCALA PARA MENSURAÇÃO \\ DA IMPORTÂNCIA PERCEBIDA PELOS \\ DOCENTES SOBRE A ABORDAGEM \\ SOCIOAMBIENTAL NOS CURSOS DE \\ ADMINISTRAÇÃO DE EMPRESAS
}

CARLA VANESSA PINTO DE MACEDO

Bacharel em Administração pelo Departamento de Administração da Universidade Estadual do Ceará (Uece).

Consultora organizacional da Innesco Consultoria Organizacional.

Rua Almeida Prado, 154, Papicu, Fortaleza - CE - Brasil - CEP 60176-085

E-mail:vanessa@innesco.com.br

\section{ANA AUGUSTA FERREIRA DE FREITAS}

Doutora pelo Departamento de Engenharia de Produção da

Universidade Federal de Santa Catarina (UFSC).

Professora do Departamento de Administração da Universidade Estadual do Ceará (Uece).

Avenida Paranjana, 1.700, Itaperi, Fortaleza - CE - Brasil - CEP 60740-000

E-mail: freitas8@terra.com.br

\section{DIEGO DE SOUSA GUERRA}

Mestre em Administração pela Universidade Estadual do Ceará (Uece).

Professor do Departamento de Administração da Universidade Federal do Ceará (UFC). Avenida Tenente Raimundo Rocha, s/n, Cidade Universitária, Juazeiro do Norte - CE - Brasil - CEP 63040-360

E-mail: diegoguerra@cariri.ufc.br 


\section{RESUMO}

As empresas representam uma entidade de grande poder sobre a sociedade com relação à sustentabilidade. As decisões tomadas pelas organizações geram impactos significativos sobre a sociedade. Nesse sentido, torna-se importante saber qual é a importância atribuída pelos profissionais de educação a temas como gestão ambiental e sustentabilidade, principalmente em cursos de administração, já que eles são o principal veículo de formação dos futuros gestores. Essa foi a preocupação de Costa et al. (2008), quando os autores avaliaram a importância atribuída por professores para a área da gestão ambiental. O presente trabalho constitui-se uma extensão daquela pesquisa, à medida que se busca abordar conceitos sugeridos pelos autores, mas ainda não contemplados. O objetivo geral é a construção de uma escala para mensuração da importância da abordagem socioambiental nos cursos de administração de empresas na percepção dos docentes. O mapeamento dos constructos e sua forma de operacionalização foram obtidos por meio da revisão de literatura e da avaliação de pesquisadores doutores da área. Após essa primeira fase, realizou-se uma análise fatorial confirmatória, e os testes sugerem que as características psicométricas de um bom instrumento foram atingidas. A aplicação do instrumento com roo professores mostrou que estes entendem que uma boa formação em administração necessita do envolvimento com questões socioambientais. Segundo eles, os cursos de administração não abordam de forma satisfatória a temática socioambiental, nem incentivam a abordagem desse tema dentro da sala de aula. Além disso, há uma descrença por parte desses profissionais quanto às reais preocupações das empresas com os temas sustentáveis. Embora a maioria tenha formado conceitos bem próximos do conceito mais usual para definição de sustentabilidade, os aspectos econômi-

76 cos, sociais e culturais não foram citados. Finalmente, poucos indicam a forma como o conceito é tratado, ou seja, não há menções relevantes a projetos de pesquisa e/ou de intervenção organizacional. 


\section{PALAVRAS-CHAVE}

Sustentabilidade; Abordagem socioambiental; Instrumento de mensuração; Cursos de administração; Percepção dos professores.

\section{INTRODUÇÃO}

Formar pessoas e profissionais preocupados com os problemas socioambientais deve estar entre as responsabilidades educacionais das instituições de ensino. Segundo Sordi (2005, p. 30), "produzir qualidade no campo educacional implica pronunciar-se sobre que tipo de homem queremos formar para produzir um determinado tipo de sociedade no qual faça sentido viver". Nesse sentido, o papel das instituições educacionais, como formadoras da sociedade, deve ser o de instigar o debate e proporcionar informações consistentes acerca dos problemas sociais e ambientais e da responsabilidade que se tem sobre esses problemas.

Além das instituições de ensino e do governo, as empresas representam outra entidade de grande poder sobre a sociedade com relação à sustentabilidade. As decisões tomadas dentro dessas organizações podem gerar impactos significativos sobre a sociedade e sobre o meio ambiente. A proporção que essa temática tem tomado dentro das empresas traz como consequência uma carência de profissionais com uma formação voltada para essas questões. É nesse contexto que se destaca a importância da abordagem de temáticas como: a sustentabilidade e a responsabilidade socioambiental na formação dos administradores e nos projetos pedagógicos das instituições de ensino superior (IES) responsáveis pela formação desses profissionais.

Nesse sentido, torna-se importante saber qual é a importância atribuída pelos profissionais de educação a temas como gestão ambiental e sustentabilidade, em cursos de administração, já que eles são agentes ativos no processo de aprendizagem, juntamente com os discentes. Essa foi a preocupação de Costa et al. (2008), quando os autores avaliaram a importância atribuída por professores de IES em administração para a área da gestão ambiental, considerando sua importância para a formação em administração. O presente trabalho constitui-se uma extensão daquela pesquisa, à medida que se busca abordar conceitos sugeridos pelos autores, mas ainda não contemplados em suas pesquisas, como sustentabilidade e responsabilidade social. O objetivo geral é a construção de uma escala para mensuração da importância da abordagem socioambiental nos cursos de administração de empresas na percepção dos docentes. 
O trabalho se estrutura da seguinte forma: a seção seguinte traz uma fundamentação teórica sobre sustentabilidade e responsabilidade social, onde se busca o esteio teórico para suas principais dimensões. Essa seção será seguida de outras que tratarão dos aspectos metodológicos da pesquisa, seus resultados, discussões e considerações finais.

\section{FUNDAMENTAÇÃO TEÓRICA}

O desenvolvimento insustentável praticado nos últimos séculos e as mazelas sociais e ambientais decorrentes deste pedem um posicionamento das instituições de ensino (IEs), lócus prioritário para o desenvolvimento de projetos e pessoas capazes de mudar esse cenário. As IEs ocupam, junto à sociedade, um papel relevante na construção do compromisso com o comportamento ético e responsável. Nessa perspectiva, a sustentabilidade, a gestão ambiental e a responsabilidade social são conceitos a serem desenvolvidos e estimulados na mente dos estudantes. As universidades devem utilizar seu potencial intelectual, técnico e tecnológico em favor de uma consciência e da formação humanística de seus alunos (SORDI, 2005).

Embora a proposta esteja relacionada à educação de forma geral, as IES, em especial, têm o papel de modificar o sistema educacional, de forma a incorporar na formação acadêmica os princípios do desenvolvimento sustentável. A caminhada para uma sociedade mais justa, consciente e sustentável se inicia pela compreensão da sustentabilidade. A discussão em sala de aula, principalmente junto aos alunos dos cursos administração de empresas, abordando assuntos como a responsabilidade social e ambiental, é de fundamental importância, pois estes terão um papel relevante na busca por uma sociedade sustentável. Os discentes são muitas vezes responsáveis por levar para as organizações empresariais a preocupação com essa temática. São eles que futuramente vão estar à frente dessas empresas, ou seja, uma mudança no comportamento desses alunos implica uma mudança nas ações das empresas (GONÇALVES-DIAS et al., 2009).

No entanto, apesar da intensa discussão que vem sendo cumprida no mundo acadêmico, não há mudanças significativas na adoção do ensino ambiental (GONÇALVES-DIAS et al., 2009; PINHEIRO et al., 20I0). Ferreira e Ferreira (2008), em pesquisa realizada com IES no Estado de Santa Catarina, constataram que $45 \%$ dos cursos de Administração não contam com disciplinas relacionadas com a questão socioambiental na matriz curricular. Dentre as IES que apresentam tais disciplinas, a maioria é de escolas particulares (93\%) e as oferecem no regime optativo. Esses resultados corroboram os argumentos de Payne 
(2006) e Cole (2007) sobre a necessidade de uma profunda mudança filosófica e paradigmática relacionada à abordagem curricular da educação ambiental, bem como a mudança das práticas pedagógicas adotadas.

Ainda nessa perspectiva, Kruglianskas (I993), em convergência com os estudos apresentados por Strife (20I0), Gonçalves-Dias et al. (2009), Jacobi (2003) e Barbieri (2004), apresentou quatro desafios a serem considerados para a inserção da temática nos cursos de graduação em administração de empresas (Quadro I).

\section{QUADRO I}

DESAFIOS PARA INSERÇÃO DA TEMÁTICA AMBIENTAL NO CURSO DE ADMINISTRAÇÃO

\begin{tabular}{ll}
\hline DESAFIOS & COMENTÁRIOS \\
\hline $\begin{array}{l}\text { Institucionalização } \\
\text { da temática }\end{array}$ & $\begin{array}{l}\text { Refere-se à forma como a questão ambiental tem sido introduzida nos } \\
\text { ou na criação de programas e centros de estudos dedicados ao tema. } \\
\text { O fator de sucesso, independente da abordagem, é a existência de } \\
\text { professores comprometidos. }\end{array}$ \\
\hline $\begin{array}{l}\text { Engajamento } \\
\text { de atores-chave } \\
\text { externos }\end{array}$ & $\begin{array}{l}\text { Objetiva trazer relevância para a sociedade com os programas de } \\
\text { gestão ambiental, envolvendo indivíduos das esferas organizacionais } \\
\text { e/ou governamentais. }\end{array}$ \\
\hline Abordagem didática & $\begin{array}{l}\text { Refere-se ao desafio de alterar as abordagens tradicionais para } \\
\text { ambiental, inserindo a gestão ambiental nas disciplinas tradicionais e } \\
\text { não concentrando estas discussões em uma disciplina específica. }\end{array}$ \\
\hline Perspectivas & $\begin{array}{l}\text { Aborda a necessidade de apresentar a gestão ambiental como uma } \\
\text { oportunidade de desenvolvimento de carreira, em que profissionais } \\
\text { profissionais }\end{array}$ \\
\hline
\end{tabular}

Fonte: Kruglianskas (I993), adaptado por Pinheiro et al. (2010).

Cooperrider (2008) explica que o que acontece dentro das empresas está diretamente ligado ao que é ensinado nas universidades, e que isso ocorre porque tudo o que é aprendido na escola, incluindo os valores e princípios morais, impacta no sistema. Para o autor, a questão da sustentabilidade é o desafio de uma transformação cultural, do surgimento de uma nova cultura que induza os membros da sociedade a atuar nos seus campos de atividade com o compromisso 
de criar valor, mas em conexão com o todo. Essa é uma nova competência individual e social a ser criada.

Nesse contexto, o docente é uma das principais peças no processo de formação desses universitários e na inserção desse conteúdo no currículo acadêmico, embora ele não seja o único responsável pela propagação da educação para a sustentabilidade. Segundo Gonçalves-Dias et al. (2009), o engajamento de atores-chave externos é a forma de assegurar que os programas de gestão ambiental sejam relevantes para a sociedade. O envolvimento de pessoas da comunidade empresarial, de órgãos governamentais e organizações não governamentais pode ocorrer por meio de diferentes papéis, tais como: orientadores, professores, palestrantes, patrocinadores e empregadores.

Além disso, interligar os valores e as práticas do desenvolvimento sustentável ao aprendizado do aluno em torno do conceito de desenvolvimento sustentável requer um processo de ensino que permita a vivência do aluno com esses princípios. Diante desse desafio, diversas pesquisas vêm discutindo a importância desse tema dentro das universidades e qual seria a melhor forma de integrar as dimensões da sustentabilidade nos currículos acadêmicos, em especial para a área de administração e de negócios.

Um exemplo de pesquisas dessa natureza foi a desenvolvida por Costa et al. (2008), em que os autores discutem a importância atribuída por professores de IES em administração para a área de gestão ambiental. O trabalho de Costa et al. (2008) teve por objetivo ofertar informações a gestores de cursos e de instituições que oferecem cursos na área de administração, para que seja possível incluir nos projetos de formação de gestores a preocupação com essa área, que tende a apresentar uma grande demanda de administradores profissionais. $\mathrm{O}$ presente trabalho segue a mesma linha metodológica, adicionando elementos não incorporados na pesquisa dos referidos autores.

Jabbour, Santos e Barbieri (2008), em um estudo bibliométrico que mapeou a produção acadêmica brasileira entre os anos de 1996 e 2005, verificaram que, dos 1.785 trabalhos publicados em seis respeitados periódicos de administração, apenas 4I versavam sobre temas relacionados à questão ambiental. Os autores verificaram também uma alta concentração de autoria da produção observada, uma vez que, na ocasião, cinco instituições de pesquisa eram responsáveis por $60 \%$ da produção nacional e quatro pesquisadores detinham aproximadamente $32 \%$ dos trabalhos publicados na área.

Além das questões já abordadas, o perfil metodológico dos estudos avaliados, que geralmente adotam estratégias teórico-empíricas qualitativas, diverge das principais pesquisas acadêmicas da área, tais como as publicadas no Journal of Cleaner Production, que comumente adotam abordagens teórico-empíricas 
quantitativas (JABBOUR; SANTOS; BARBIERI, 2008). Cerca de 50\% da literatura que serviu de base para estudos dessa natureza é internacional, sendo os mais citados os estudos de Hunt e Auster (I990) e Porter e Linde (I995). O uso recorrente de publicações estrangeiras pode ser explicado pelo número restrito de estudos sobre a temática nos periódicos nacionais (JABBOUR; SANTOS; BARBIERI, 2008).

\section{METODOLOGIA}

Esta seção apresenta os procedimentos e as decisões metodológicos seguidos no desenvolvimento da investigação empírica. Para a consecução do objetivo principal do trabalho, recorreu-se a duas fases distintas de investigação. $\mathrm{Na}$ primeira, denominada fase exploratória, procedeu-se a uma considerável revisão de literatura com o intuito de construir bases teóricas consistentes para os tópicos abordados no estudo. O mapeamento dos constructos e sua forma de operacionalização deram-se por meio da revisão de literatura especializada e pelos instrumentos de mensuração já utilizados, como o proposto por Costa et al. (2008).

Com a adoção desses procedimentos, foram identificadas cinco dimensões relacionadas à percepção dos professores sobre a importância da abordagem socioambiental nos cursos de administração de empresas, a saber:

- A primeira dessas dimensões (VLI) considera a relevância da sustentabilidade, medindo a importância desse tema para a formação em administração e para o desempenho das organizações, bem como a necessidade de abordar esse assunto em sala de aula.

- $\quad$ A segunda (VL2) trata do papel das instituições de ensino na formação da percepção socioambiental, verificando a responsabilidade destas na promoção do interesse e do envolvimento dos discentes.

- A terceira dimensão (VL3) contempla a percepção dos docentes acerca das instituições de ensino como lócus para formação de profissionais capacitados para lidar com questões socioambientais.

- A quarta (VL4) analisa a percepção dos docentes sobre o interesse do mercado em questões socioambientais, avaliando a preocupação das empresas em atuar com sustentabilidade.

- A última dimensão (VL5) mensura o interesse pessoal dos professores na temática socioambiental, verificando o desejo de eles se envolverem profissional e academicamente com assuntos socioambientais e a preocupação em abordar e discutir a sustentabilidade em sala de aula. 
As delimitações desses constructos serviram de base para a construção do instrumento de pesquisa. Trata-se de um questionário estruturado, composto por 20 afirmativas mensuradas por meio de uma escala de Likert de 5 pontos, que formam a escala, além de mais ıo questões relacionadas a informações gerais e perfil sociodemográfico dos respondentes.

O instrumento também contou com uma parte qualitativa, em que os entrevistados eram convidados a responder de forma aberta às seguintes questões: como eles definem o conceito de sustentabilidade e como costumam abordar essa temática em sala de aula. Essas questões tinham o intuito de complementar as questões de cunho quantitativo, no sentido de avaliar de que forma o conceito de sustentabilidade estava sendo interpretado pelos docentes e de que forma ele se operacionaliza na prática cotidiana do ensino. As respostas foram analisadas utilizando-se a análise de conteúdo.

Após os procedimentos preliminares de ajuste do instrumento, de avaliação por pesquisadores especialistas e de pré-teste, o questionário foi aplicado em Io० professores de IES públicas e privadas de Fortaleza-CE. A amostra continha professores que lecionavam tanto em cursos diurnos como noturnos, em universidades e faculdades isoladas, com diferentes portes. A amostra, não probabilística, foi definida por acessibilidade, e a coleta de dados foi realizada nos meses de setembro e outubro de 2010 , por meio de abordagem direta dos professores nos locais de trabalho ou do envio de surveys eletrônicas por e-mail. Importante destacar que, embora se reconheça a heterogeneidade da amostra, não foram realizadas análises estratificadas.

Na segunda fase da pesquisa, os dados foram analisados com o auxílio dos softwares Statistical Package for the Social Sciences (SPSS) e Analysis of Moment Structures (Amos). O primeiro foi utilizado para análises descritivas, testes não paramétricos e testes de confiabilidade. $\mathrm{O}$ uso do segundo software justifica-se pelo fato de que a escala proposta neste trabalho já dispõe de uma estrutura fatorial definida previamente, havendo, portanto, a necessidade de testar a sua adequação por meio da análise fatorial confirmatória (RAYKOV; MARCOULIDES, 2006).

Os missing values foram tratados utilizando o método de substituição pela média dos dados presentes daquela variável em razão da total aleatoriedade dos casos omissos. Os índices de não resposta variaram de i\% a 4\%, estando, portanto, dentro da faixa recomendada pela literatura especializada, que é de até ı०\% (cf. COSTA, 2002). Outro pressuposto testado foi a ausência de outliers, ou seja, padrões de resposta destoantes das demais observações da amostra. 


\section{ANÁLISE dOS RESULTAdOS}

A pesquisa foi realizada com docentes das mais diversas áreas do curso de graduação em administração de empresas, como: finanças, RH, estatística, marketing, direito, filosofia, logística, economia e produção. Vale ressaltar que, por se tratar de um curso muito abrangente em termos de áreas de aplicação, muitos dos professores atuam em mais de uma área ao mesmo tempo. A análise foi realizada com roo entradas de dados, e, com base nas entradas não nulas, pode-se concluir da amostra o seguinte:

- $\quad$ Entre os entrevistados, 65\% são homens e 58\% informaram ter menos de 50 anos.

- Quanto à formação, $49 \%$ dos entrevistados possuem uma formação em administração, I6\% em economia ou ciências contábeis, I8\% em engenharia, matemática ou estatística, $7 \%$ em direito e I०\% em psicologia, sociologia e cursos afins, e $6 \%$ das entradas possuem pelo menos duas formações distintas.

- Dos professores participantes da presente pesquisa, ficou constatado que $4 \%$ são apenas graduados, 25\% apenas especialistas, 50\% são mestres, I9\% doutores e $2 \%$ têm pós-doutorado. Além disto, 35\% declararam possuir algum curso ou especialização na área.

\section{ANÁLISE FATORIAL CONFIRMATÓRIA}

Para o processo de análise fatorial confirmatória, definiram-se inicialmente os parâmetros associados ao processo de avaliação das dimensões, dada a certa variação de critérios apresentada pela literatura especializada (RAMOS, 2009). Os critérios utilizados para avaliação dessa fase da pesquisa foram valores de raiz do erro quadrático médio aproximado (RMSEA) menores que o,०8; valores de índice de adequação do ajustamento (GFI) e índice de ajuste comparativo (CFI) superiores a 0,9 ; a estatística qui-quadrado $\left(\chi^{2}\right)$ menor possível e sua divisão pelos graus de liberdade (gl) menor do que 3 (HAIR et al., 2005; RAYKOV; MARCOULIDES, 2006; RAMOS, 2009; MARÔCO, 20I0). Adicionalmente, foram extraídos para cada dimensão os índices de confiabilidade composta, de variância extraída, a média dos escores fatoriais, o alfa de Cronbach e o menor critical ratio.

A Tabela I mostra os resultados obtidos para cada uma das dimensões da escala após os procedimentos de ajuste guiados pelos parâmetros supracitados e pelas alterações sugeridas pelo software Amos no item modification indices. É importante ressaltar que tal adequação só foi possível com a exclusão de alguns itens, que são listados no Quadro 2. 


\section{QUADRO 2}

\section{ITENS EXCLUÍDOS POR CONSTRUCTO}

\begin{tabular}{cl}
\hline CONSTRUCTO & ITEM \\
\hline VL2 & $\begin{array}{l}\text { Cursos de administração deveriam ter no currículo conteúdos/disciplinas sobre } \\
\text { desenvolvimento sustentável. }\end{array}$ \\
\hline VL2 & $\begin{array}{l}\text { Cursos de administração deveriam ter projetos relacionados a questões sociais } \\
\text { e ambientais. }\end{array}$ \\
\hline VL5 & $\begin{array}{l}\text { Probabilidade de trabalhar (no mercado não acadêmico) com questões } \\
\text { socioambientais. }\end{array}$ \\
\hline
\end{tabular}

Fonte: Elaborado pelos autores.

Para a análise da unidimensionalidade, foi utilizado o índice CFI, que tem como parâmetro mínimo o valor de o,9. A confiabilidade dos construtos foi verificada pelos valores de variância extraída, que deve ser maior que 0,5, além do alfa de Cronbach e da confiabilidade composta, que devem ser maiores que 0,7 (HAIR JR. et al., 2005; RAMOS, 2009). Conforme se verifica na Tabela I, a unidimensionalidade e a confiabilidade dos construtos foram asseguradas por índices mínimos de CFI de 0,997, variâncias extraídas de 0,619, alfas de 0,774 e confiabilidades compostas de 0,709 .

A validade convergente, que avalia o grau de correlação positiva das variáveis com os seus pares da mesma dimensão (DEVELLIS, I99I), foi testada pela análise dos $t$-values. Valores superiores a I,96 $(\mathrm{p}<0,05)$ indicam uma boa adequação. Na Tabela I, pode-se observar que o menor valor de critical ratio (CR) encontrado foi de 4,399, muito superior aos padrões mínimos exigidos para essa medida. Todos os valores observados foram significativos a $\mathrm{p}<0,00 \mathrm{I}$, o que sugere a validade convergente para cada uma das dimensões.

\section{TABELA I}

MEDIDAS FINAIS DE AJUSTE POR CONSTRUCTO

\begin{tabular}{lccccc}
\hline \multirow{2}{*}{ MEDIDA } & \multicolumn{5}{c}{ DIMENSÃO } \\
\cline { 2 - 6 } & VL1 & VL2 & VL3 & VL4 & VL5 \\
\hline Confiabilidade composta & 0,709 & 0,759 & 0,752 & 0,718 & 0,793 \\
\hline Variância extraída & 0,695 & 0,788 & 0,701 & 0,619 & 0,730 \\
\hline
\end{tabular}


TABELA I (CONCLUSÃo)

MEDIDAS FINAIS DE AJUSTE POR CONSTRUCTO

\begin{tabular}{|c|c|c|c|c|c|}
\hline \multirow{2}{*}{ MEDIDA } & \multicolumn{5}{|c|}{ DIMENSÃO } \\
\hline & VL1 & VL2 & VL3 & VL4 & VL5 \\
\hline Média dos escores & 0,770 & 0,702 & 0,701 & 0,604 & 0,671 \\
\hline Menor critical ratio* & 5,941 & 7,802 & 5,277 & 4,399 & 4,429 \\
\hline Qui-quadrado (X²) & 0,513 & 0,425 & 1,348 & 0,413 & 1,069 \\
\hline Graus de liberdade (gl) & 2 & 1 & 1 & 2 & 1 \\
\hline$X^{2} / g \mid$ & 0,256 & 0,425 & 1,348 & 0,707 & 1,069 \\
\hline Valor de $p$ & 0,774 & 0,514 & 0,246 & 0,493 & 0,301 \\
\hline GFI & 0,977 & 0,997 & 0,991 & 0,993 & 0,993 \\
\hline $\mathrm{CFI}$ & 1,000 & 1,000 & 0,997 & 1,000 & 1,000 \\
\hline RMSEA & 0,000 & 0,000 & 0,059 & 0,000 & 0,026 \\
\hline Alfa final & 0,831 & 0,862 & 0,774 & 0,788 & 0,792 \\
\hline
\end{tabular}

* Todos os valores significativos a $\mathrm{p}<\mathrm{0,00I}$.

Fonte: Elaborada pelos autores.

A validade discriminante foi testada a partir da comparação de dois modelos de correlação entre os pares de constructo. O primeiro foi analisado assumindo que havia correlação perfeita entre as variáveis latentes, enquanto, no segundo, nenhuma correlação foi previamente definida. Gosling (200I), baseada no trabalho de Moorman e Miner (I998), sugere a existência de validade discriminante quando a diferença do teste qui-quadrado do modelo de correlação perfeita supera em 3,84 o modelo de correlação livre. Os resultados da Tabela 2 indicam a existência de validade discriminante para a escala, visto que a menor diferença observada entre os construtos foi de I9,033. 
TABELA 2

VALIDADE DISCRIMINANTE DA ESCALA

\begin{tabular}{cccc}
\hline $\begin{array}{c}\text { CONSTRUCTOS } \\
\text { CORRELACIONADOS }\end{array}$ & $\begin{array}{c}\chi^{2} \text { COM CORRELAÇÃO } \\
\text { PERFEITA }\end{array}$ & $\begin{array}{c}\chi^{2} \text { COM CORRELAÇÃO } \\
\text { LIVRE }\end{array}$ & DIFERENÇA \\
\hline VL1 - VL2 & 84,911 & 24,489 & 60,422 \\
\hline VL1 - VL3 & 70,026 & 24,133 & 45,893 \\
\hline VL1 - VL4 & 75,454 & 15,222 & 60,232 \\
\hline VL1 - VL5 & 78,081 & 17,502 & 60,579 \\
\hline VL2 - VL3 & 86,242 & 33,905 & 52,337 \\
\hline VL2- VL4 & 78,558 & 30,332 & 48,226 \\
\hline VL2 - VL5 & 78,211 & 23,664 & 54,547 \\
\hline VL3 - VL4 & 80,183 & 24,824 & 55,359 \\
\hline VL3 - VL5 & 73,962 & 10,241 & 63,721 \\
\hline VL4 - VL5 & 36,547 & 17,514 & 19,033 \\
\hline
\end{tabular}

Fonte: Elaborada pelos autores.

De maneira geral, os resultados descritos nesta seção sugerem que as características psicométricas de um bom instrumento foram atingidas, conforme apresentado a seguir:

- A validade de conteúdo foi atestada por pesquisadores especialistas na área e ratificada pelo pré-teste realizado com uma pequena amostra de respondentes típicos na fase preliminar do trabalho de campo.

- A validade de constructo, ou seja, as validades convergente e discriminante, foi chancelada pelos índices de ajustamento propostos pela literatura, bem como pela verificação da diferença do teste qui-quadrado entre os modelos de correlação perfeita e livre.

- Os critérios utilizados para a avaliação da confiabilidade dos constructos, como o alfa de Cronbach e a confiabilidade composta, indicaram índices satisfatórios em todas as verificações. 


\subsection{ANÁLISE DESCRITIVA}

Para uma análise da importância da sustentabilidade e das questões socioambientais para o curso administração de empresas, foram avaliadas as média obtidas em três itens que verificavam essa questão. Em uma escala convencional de Likert de 5 pontos, o índice médio encontrado foi superior a 4 e o desvio-padrão apresentou-se inferior a I (Tabela 3). Juntos esses fatores indicaram o entendimento dos professores de que uma boa formação em administração necessita do envolvimento com questões socioambientais e da concepção dessa temática como uma questão de grande relevância para a formação em administração.

\section{TABELA 3}

RELEVÂNCIA DA SUSTENTABILIDADE

PARA A ADMINISTRAÇÃO DE EMPRESAS

\begin{tabular}{lcc}
\hline ITEM & MÉDIA & DESVIO-PADRÃO \\
\hline $\begin{array}{l}\text { A sustentabilidade é uma questão relevante para o desempenho } \\
\text { das organizações empresariais. }\end{array}$ & 4,41 & 0,818 \\
\hline $\begin{array}{l}\text { A sustentabilidade é um assunto de grande importância para a } \\
\text { formação em administração. }\end{array}$ & 4,62 & 0,763 \\
\hline $\begin{array}{l}\text { Uma boa formação em administração necessita de uma formação } \\
\text { envolvida com questões ambientais. }\end{array}$ & 4,60 & 0,725 \\
\hline
\end{tabular}

Fonte: Elaborada pelos autores.

Com relação à análise do papel da universidade no desenvolvimento do aprendizado sobre questões sociais e ambientais, os docentes demonstraram que, para eles, as IES são responsáveis pelo desenvolvimento e pelo aumento da compreensão dos alunos com relação a assuntos sociais e ambientais. Na questão que avaliava essa temática, a média foi superior a 4, e o desvio-padrão foi inferior a I. Para promoverem o desenvolvimento desse aprendizado, as IES deveriam inserir conteúdos e disciplinas relacionados com essa temática em seu currículo, bem como avaliar o conhecimento dos alunos sobre sustentabilidade e responsabilidade socioambiental. Confirmando essa afirmativa, os quatro itens que avaliavam essa questão apresentaram média superior a 4 e desvio-padrão inferior a I, o que representa uma baixa divergência na opinião dos professores (Tabela 4). 
TABELA 4

PAPEL DA UNIVERSIDADE NO DESENVOLVIMENTO DO APRENDIZADO SOBRE QUESTÕES SOCIOAMBIENTAIS

\begin{tabular}{lcc}
\hline ITEM & MÉDIA & DESVIO-PADRÃO \\
\hline $\begin{array}{l}\text { Escolas de administração deveriam oferecer oportunidades } \\
\text { para que os estudantes melhorassem sua compreensão sobre } \\
\text { sustentabilidade. }\end{array}$ & 4,68 & 0,601 \\
\hline $\begin{array}{l}\text { Cursos de administração deveriam avaliar os conhecimentos sobre } \\
\text { sustentabilidade dos alunos. }\end{array}$ & 4,24 & 0,996 \\
$\begin{array}{l}\text { Os cursos de adminstração deveriam envolver os estudantes em } \\
\text { assuntos socioambientais. }\end{array}$ & 4,60 & 0,682 \\
\hline $\begin{array}{l}\text { Estudantes de administração deveriam ser incentivados por suas } \\
\text { instituições de ensino a se envolver em projetos socioambientais. }\end{array}$ & 4,49 & 0,732 \\
\hline
\end{tabular}

Fonte: Elaborada pelos autores.

Os três itens que mensuravam a abordagem socioambiental da universidade para o mercado apresentaram médias inferiores a 3 e desvios de aproximadamente I, conforme pode ser observado na Tabela 5. Esses resultados indicam que os professores acreditam que os cursos de administração não abordam de forma satisfatória a temática socioambiental, nem incentivam a abordagem desse tema dentro da sala de aula. Ainda segundo a percepção dos docentes, há uma carência de administradores capacitados para lidar profissionalmente com o assunto. Esses resultados corroboram a tese de que, apesar da incontestável importância do debate de temas relacionados às questões socioambientais, as discussões inerentes a essa temática estão sendo negligenciadas pelos cursos de graduação em administração (FERREIRA; FERREIRA, 2008; GONÇALVES-DIAS et al., 2009; PINHEIRO et al., 20IO).

\section{TABELA 5}

A ABORDAGEM SOCIOAMBIENTAL DA UNIVERSIDADE PARA O MERCADO

\begin{tabular}{lcc}
\hline ITEM & MÉDIA & DESVIO-PADRÃO \\
\hline $\begin{array}{l}\text { Os cursos de administração abordam de forma satisfatória a } \\
\text { temática socioambiental. }\end{array}$ & 2,53 & 1,029 \\
\hline
\end{tabular}

(continua) 


\section{TABELA 5 (Conclusão)}

\section{A ABORDAGEM SOCIOAMBIENTAL DA \\ UNIVERSIDADE PARA O MERCADO}

\begin{tabular}{lcc}
\hline ITEM & MÉDIA & DESVIO-PADRÃO \\
\hline $\begin{array}{l}\text { Há profissionais no mercado com formação adequada para } \\
\text { atender a essa demanda e capacitados para lidar com questões } \\
\text { socioambientais. }\end{array}$ & 2,54 & 0,989 \\
\hline $\begin{array}{l}\text { Os cursos de administração incentivam/apoiam/exigem a } \\
\text { abordagem da temática socioambiental em sala de aula. }\end{array}$ & 2,78 & 1,124 \\
\hline
\end{tabular}

Fonte: Elaborada pelos autores.

Em relação à percepção dos professores sobre o interesse do mercado em questões socioambientais, os professores apontaram, de forma bastante modesta, haver interesse do mercado nas questões socioambientais. Todas as afirmativas apresentam médias inferiores a 4 pontos e desvios superiores a I. O destaque desse constructo está relacionado à questão que propunha haver uma preocupação das empresas em atuar com sustentabilidade dentro das questões socioambientais, que obteve média 3,09, bem próxima ao ponto médio da escala. Esse resultado demonstra indícios de descrença dos professores quanto às reais preocupações das empresas com os temas sustentáveis, mesmo havendo uma tendência positiva (média $=3,73$ ), e relativamente modesta, em relação à percepção dos professores na questão que avalia a demanda por administradores com formação compatível com a área (Tabela 6).

\section{TABELA 6}

INTERESSE DO MERCADO EM QUESTÖES SOCIOAMBIENTAIS

$$
\text { ITEM }
$$$$
\text { MODA MÉDIA DESVIO-PADRÃO }
$$

Faz parte das exigências do mercado que a formação acadêmica dos administradores passe pela formação socioambiental.

$4 \quad 3,35 \quad 1,201$

A formação de administradores com ênfase em responsabilidade socioambiental facilita na sua colocação no mercado de trabalho.

$4 \quad 3,48 \quad 1,105$

(continua) 
TABELA 6 (CONCLUSÃo)

INTERESSE DO MERCADO EM QUESTÖES SOCIOAMBIENTAIS

\begin{tabular}{lccc}
\hline ITEM & MODA & MÉDIA & DESVIO-PADRÃO \\
\hline $\begin{array}{l}\text { Há no mercado demanda por administradores com uma } \\
\text { formação voltada para o social e o ambiental. }\end{array}$ & 4 & 3,73 & 1,081 \\
\hline $\begin{array}{l}\text { As empresas estão preocupadas em atuar com } \\
\text { sustentabilidade dentro de questões socioambientais. }\end{array}$ & 4 & 3,09 & 1,093 \\
\hline
\end{tabular}

Fonte: Elaborada pelos autores.

Quanto à probabilidade de os professores inserirem essas questões entre seus temas de ensino e quanto à probabilidade de os alunos se envolverem academicamente em projetos socioambientais, as médias obtidas foram de aproximadamente 4 e os desvios-padrão próximos a I. Já com relação ao envolvimento profissional no mercado não acadêmico, o interesse em atuar em questões socioambientais foi menor que o percebido nos itens anteriores, com uma média de aproximadamente 3,5 e um desvio-padrão superior a I (Tabela 7).

\section{TABELA 7}

O INTERESSE PESSOAL DOS PROFESSORES

NA TEMÁTICA SOCIOAMBIENTAL

\begin{tabular}{lcc}
\hline ITEM & MÉDIA & DESVIO-PADRÃO \\
\hline $\begin{array}{l}\text { Probabilidade de inserir o desenvolvimento sustentável entre os } \\
\text { meus temas de ensino. }\end{array}$ & 4,06 & 0,941 \\
\hline $\begin{array}{l}\text { Probabilidade de inserir as questões socioambientais entre os } \\
\text { meus temas de pesquisa. }\end{array}$ & 3,96 & 0,875 \\
\hline $\begin{array}{l}\text { Probabilidade de me envolver academicamente em projetos de } \\
\text { sustentabilidade socioambiental. }\end{array}$ & 3,93 & 0,946 \\
\hline
\end{tabular}

Fonte: Elaborada pelos autores.

Considerando a importância que a temática socioambiental tem alcançado nos últimos tempos, outra questão analisada foi o conhecimento que os professores têm acerca desse assunto. Para isso, foi solicitado aos professores que definissem seu conceito de sustentabilidade. Os conceitos obtidos foram comparados ao conceito de sustentabilidade preconizado pelo relatório de Brundtland Nosso futuro em comum - elaborado pela Comissão Mundial sobre Meio Ambiente 
e Desenvolvimento: "Atender as necessidades do presente sem comprometer a capacidade de as gerações futuras atenderem também as suas” (CMAAD, I99I, p. 46), ou seja, promover o desenvolvimento de modo a garantir a renovação e conservação dos recursos para que as próximas gerações continuem usufruindo deles. É relevante destacar que aqui não se trata exclusivamente da preservação e manutenção dos recursos ambientais, embora estes sejam de suma relevância, deve-se lembrar que a cultura, a economia e o bem-estar social são fatores igualmente essenciais para as gerações que ainda virão. Analisando as respostas obtidas, chegou-se ao seguinte resultado:

- Dos entrevistados, $3 \%$ informaram não possuir nenhum conceito acerca da sustentabilidade.

- Dos entrevistados, II\% formaram um conceito equivocado, associaram sustentabilidade a fatores como geração de renda, urbanismo, lazer, sobrevivência da empresa no mercado competitivo etc.

- Em 86\% dos casos, os conceitos apresentados estavam relacionados com preservação ambiental e manutenção dos recursos naturais, garantindo sua disponibilidade às gerações futuras.

Deve-se ressaltar que continuidade foi o termo mais citado pelos entrevistados em suas definições. Embora a maioria dos professores tenha formado conceitos bem próximos do conceito mais usual para definição de sustentabilidade, os aspectos econômicos, sociais e culturais não foram citados pela maioria (53\%) dos entrevistados. O fato do esquecimento desses fatores deixou claro que grande parte dos entrevistados entende que os aspectos ambientais são os mais relevantes quando se trata de sustentabilidade, mas é importante ressaltar aqui que todos os aspectos já citados são de suma importância na construção de uma sociedade sustentável.

Ainda com o objetivo de avaliar a relação dos professores com questões ligadas à temática socioambiental, foi perguntado se eles costumam abordar essa temática em sala de aula e, em caso positivo, de que forma o fazem. Os dados mostram que $85 \%$ dos professores abordam esse assunto durante suas aulas, e a maioria reconhece que sua disciplina tem uma relação com a temática. É interessante que esses dados contrastam com aquilo que esses mesmos professores percebem dos cursos de administração em geral (Tabela 6). Na verdade, na Tabela 6 , apresenta-se o que eles acreditam que acontece nos cursos de administração, enquanto, na parte qualitativa, estavam revelando a sua própria práxis.

Finalmente, poucos indicam a forma como o conceito é tratado, ou seja, não há menções relevantes a projetos de pesquisa e/ou de intervenção organizacional. Outras metodologias de ensino, como estudos de caso, não foram citadas. 
Além disso, nas IES que possuem projetos interdisciplinares, não fica clara a inserção da temática como assunto transversal a ser tratado por professores de outras disciplinas.

\section{CONSIDERAÇÕES FINAIS}

Os administradores têm um papel relevante na transformação da consciência ambiental, posto que espera-se que uma parte deles ocupe cargos estratégicos nas organizações, com reflexos na mudança de valores e comportamentos sociais. Esse fato esclarece por que a educação voltada para os desafios socioambientais se apresenta de maneira tão decisiva na formação dos administradores. O modo como se vê a administração, como uma atividade que deve buscar atender exclusivamente aos interesses das organizações, se contrapõe às atuais perspectivas da sociedade que indicam como instrumento de competitividade empresarial a necessidade de incluir o meio ambiente nas decisões empresariais.

O destaque das questões sociais e ambientais precisa ser discutido em sala de aula. A capacitação desses graduandos não só com relação à sua função empresarial e profissional, mas também social, é um desafio dos educadores e uma necessidade da sociedade. Para que se alcance uma formação voltada para o social e o ambiental, são necessários profissionais capacitados para inserir essa temática na vida acadêmica dos alunos. A inserção dessa problemática na formação dos administradores é uma responsabilidade que não pode ser negligenciada pelas IES.

O presente trabalho traz uma contribuição metodológica relevante quando apresenta uma proposta de escala para mensuração da importância da abordagem socioambiental nos cursos de administração na percepção dos docentes. A presente pesquisa avança também em relação a trabalhos anteriores (por exemplo, COSTA et al., 2008), à medida que amplia a discussão sobre a preocupação ambiental, incluindo temas como sustentabilidade e responsabilidade social. Além disso, a pesquisa oferece algumas evidências empíricas que podem ajudar a superar os desafios identificados em trabalhos prévios. Em relação à institucionalização da temática ambiental, por exemplo, a pesquisa mostra indícios de que não bastam apenas professores comprometidos. Uma boa parte deles precisa ser treinada, por exemplo, a partir de programas de capacitação, antes de inserirem a temática em suas disciplinas.

Dentro desse contexto, a presente pesquisa revelou que, embora a importância atribuída a essa temática seja relevante, ainda não se percebem grandes ações voltadas para essa questão na práxis de ensino. Praticamente não são ofer- 
tadas aos alunos oportunidades de se envolverem em projetos relacionados a esse assunto, sejam eles de caráter de intervenção ou de pesquisa.

Isso deixa claro que, embora o apelo da sociedade com relação à preocupação com o social e o ambiental tenha sido crescente nos últimos anos, essa preocupação ainda não atravessou fortemente os muros das IES, e estas ainda não têm cumprido seu papel. A sustentabilidade e as questões socioambientais relacionam-se com as mais diversas disciplinas, como economia, direito, administração da produção, logística, marketing, entre outras. A multidisciplinaridade facilita sua abordagem em sala, podendo ser realizada sob as mais diversas perspectivas. Tal interdisciplinaridade poderia ser objeto dos projetos interdisciplinares que são comuns nos cursos de administração.

Os resultados ainda mostraram que os docentes têm consciência da sua importância no desenvolvimento da compreensão dos discentes com relação a assuntos sociais e ambientais e se mostram mais interessados em se envolver academicamente do que profissionalmente com essas questões, além de perceberem pouco interesse do mercado em temáticas socioambientais. Segundo eles, uma boa formação em administração necessita do envolvimento com questões socioambientais, pois trata-se de uma temática relevante que ainda não foi adequadamente abordada nos cursos de administração. Finalmente, quando avaliados em termos de conhecimento sobre o assunto, a maioria dos entrevistados vincula sustentabilidade a aspectos ambientais, negligenciando as questões econômicas, culturais e sociais subjacentes ao conceito.

Como implicação gerencial imediata, sugere-se aos gestores de IES que forneçam capacitação aos seus professores não somente sobre o assunto, mas principalmente sobre os recursos didáticos disponíveis para tratá-los em suas disciplinas, de forma a despertar nesses profissionais o interesse por essa área e desse modo promover desenvolvimento de discussões em sala de aula acerca dessa temática. O melhor desenvolvimento de valores pessoais sobre sustentabilidade nos estudantes figura como implicação social deste estudo, uma vez que as decisões desses futuros gestores serão reflexo da qualidade dessa educação.

Deve-se registrar que a amostra utilizada nesta pesquisa tem uma natureza não probabilística. Isso significa que, apesar de o trabalho contribuir com a literatura pertinente oferecendo à comunidade uma escala que pode ser utilizada em outros contextos, seus resultados não podem ser generalizados.

Como sugestão para pesquisas futuras, indica-se a aplicação do instrumento proposto com diferentes amostras, com o objetivo de verificar se os resultados aqui encontrados repetem-se em outros contextos. Estudos de adaptação e/ou validação da escala também configuram uma boa perspectiva de futuras contribuições metodológicas. 


\section{A SCALE FOR MEASURING THE IMPORTANCE OF SOCIO-ENVIRONMENTAL APPROACH IN BUSINESS SCHOOLS}

\section{ABSTRACT}

Companies represent an entity of great power over society in relation to sustainability. Decisions taken by organizations generate significant impacts on society. In this sense, it is important to know importance attached by professionals of education in topics such as environmental management and sustainability, particularly in business schools, since they are the primary vehicle for training future managers. This was the concern of Costa et al. (2008), when authors assessed importance attached by teachers to the area of environmental management. This study represents an extension of that research, as it seeks to address concepts suggested by the authors, but still covered. The overall objective of study is to propose a scale to measure the importance of the approach in the Socio-Environmental Business courses in the perception of teachers. Combination of itens and their way of operation is given by literature review and through the evaluation of PhD researchers in the area. In a second phase, there was a confirmatory factor analysis which present adequate results for a good scale fit. The application of the questionnaire with roo teachers showed that they understand that a good management education requires engagement with social and environmental issues. They perceive business courses do not adequately address social and environmental issues, nor encourage this theme in the classroom. Furthermore, teachers don't believe in a real concern of companies about sustainable themes. Although most concepts are close to the most common definition of sustainability, economic, social and cultural rights were not mentioned. Finally, few indicate how the concept is treated, in other words, there isn't references to relevant research projects and/or organizational intervention.

\section{KEYWORDS}

Sustainability; Socio-environmental approach; Measurement instrument; Business schools; Teacher's perception. 


\section{UNA ESCALA PARA MEDIR LA IMPORTANCIA DEL ENFOQUE SOCIO-AMBIENTAL EN LAS ESCUELAS DE NEGOCIOS}

\section{RESUMEN}

Las empresas representan una entidad de gran poder sobre la sociedad con respecto a la sustentabilidad. Las decisiones tomadas por las organizaciones generan impactos significativos en la sociedad. En este sentido, es importante saber el real valor que los profesionales de educación le dan a los temas de gestión ambiental y sustentabilidad, principalmente cuando se habla de los cursos académicos de administración de empresas ya que los mismos son responsables por la graduación de los futuros gestores. Esta es la preocupación de Costa et al. (2008) cuando los autores evaluaron la importancia que los profesores le dieron al tema de gestión ambiental. El presente trabajo es una extensión de aquella investigación en la medida que se trata los conceptos sugeridos por los autores, todavía no contemplados en sus estudios. El objetivo de este estudio es proponer una escala que se pueda medir la importancia del abordaje socio-ambiental en los cursos de administración por parte de los docentes. La combinación de los artículos y su forma de manejo se dieron a través de la revisión de literatura y por medio de la evaluación de los doctores especializados. En un segundo momento se ha realizado un análisis factorial donde se ha podido confirmar tal hecho. La aplicación del instrumento con roo profesores ha mostrado que ellos entienden que la calidad de la graduación en administración esta relacionada directamente con los temas socio-ambientales. Según los mismos, los cursos no abordan el tema de manera satisfactoria y tampoco la incentivan en las clases. Además, no hay una creencia por parte de estos profesionales respecto a las reales preocupaciones de las empresas con los temas de sustentabilidad. Aunque la mayoría haya desarrollado el concepto de sustentabilidad parecido al concepto mas usual, los aspectos económicos, sociales, y culturales no fueron citados. Finalmente, pocos indican la manera como el concepto es tratado, o sea, no hay menciones relevantes a los proyectos de investigación y/o de intervención organizativo.

\section{pAlabras CLAVE}

Sustentabilidad; Abordaje socio-ambiental; Instrumentos mensurables; Cursos de administración; Percepción de los profesores. 


\section{REFERÊNCIAS}

ASHLEY, P. A. Ética e responsabilidade social nos negócios. São Paulo: Saraiva, 2002.

BARBIERI, J. C. Educação ambiental e a gestão ambiental em cursos de graduação em administração: objetivos, desafios e propostas. Revista de Administração Pública, v. 38, n. 6, p. 919-946, 2004. COLE, A. Expanding the field: revisiting environmental education principles through multidisciplinary frameworks. Journal of Envitonmental Education, v. 38, n. 2, p. 35-46, 2007.

COOPERRIDER, D. Café com sustentabilidade: empresas, universidades e sociedade num mundo sustentável. São Paulo: Fecomercio, 2008. Disponível em: <http://www.febraban.org.br/Febraban.asp?id_pagina=93>. Acesso em: 20 nov. 2009 .

COSTA, F. C. Relacionamento entre influências ambientais e o comportamento de compra por impulso: um estudo em lojas físicas e virtuais. 2002. Tese (Doutorado)-Universidade de São Paulo, São Paulo, 2002.

COSTA, F. J. et al. A gestão ambiental na formação em administração: uma análise da perspectiva dos alunos. In: ENCONTRO NACIONAL DE GESTÃO EMPRESARIAL E MEIO AMBIENTE (ENGEMA), Io., 2008, Porto Alegre. Anais... Porto Alegre: Universidade Federal do Rio Grande do Sul, 2008.

CRONBACH, L. J. Coefficient alpha and the internal structure of tests. Psychometrika, v. I6, n. 3, p. I97-334, Sept. I95I.

DEVELLIS, R. F. Scale development: theory and applications. Newbury Park: Sage, I99I.

FERREIRA, D. D. M.; FERREIRA, L. F. O ensino de gestão ambiental nos cursos de administração de empresas nas IES (instituições de ensino superior) do estado de Santa Catarina: um estudo exploratório. In: CONGRESSO NACIONAL DE EXCELÊNCIA EM GESTÃO, 4., 2008, Rio de Janeiro. Anais... Rio de Janeiro: Universidade Federal Fluminense, 2008.

FIELD, A. P. Discovering statistics using SPSS for Windows: advanced techniques for the beginner. London: Sage, 2000.

GONÇALVES-DIAS, S. L. F. et al. Consciência ambiental: um estudo exploratório sobre suas implicações para o ensino de administração. RAE-eletrônica, v. 8, n. I, jan./jun. 2009. Disponível em: <http://www.fgv.br/raeeletronica>. Acesso em: 20 abr. 2010.

GOSLING, M. Estratégias de relacionamento no setor bancário brasileiro: um estudo empírico. 2002. Dissertação (Mestrado em Administração)-Universidade Federal dse Minas Gerais, Belo Horizonte, $200 I$.

HAIR JR., J. F.; ANDERSON, R. E.; TATHAM, R. L.; BLACK, W. C. Análise multivariada de dados. Tradução Adonai Schlup Sant'Anna e Anselmo Chaves Neto. 6. ed. Porto Alegre: Bookman, 2009. HAIR JR., J. F.; BABIN, B.; MONEY, A. H.; SAMOUEL, P. Fundamentos de métodos de pesquisa em administração. Tradução Lene Belon Ribeiro. Porto Alegre: Bookman, 2005.

HUNT, C. B.; AUSTER, E. R. Proactive environmental management: avoiding the toxic trap. MIT Sloan Management Review, v. 3I, n. 2, p. 7-I8, I990.

JABBOUR, C.; SANTOS, F.; BARBIERI, J. Gestão ambiental empresarial: um levantamento da produção científica brasileira divulgada em periódicos da área de Administração entre I996 e 2005. Revista de Administração Contemporânea, v. ı2, n. 3, p. 689-7I5, jul./set. 2008.

JACOBI, P. Educação ambiental, cidadania e sustentabilidade. Cadernos de Pesquisa, n. Iı8, p. I89205, mar. 2003. 
KAISER, H. F. An index of factorial simplicity. Psychometrika, v. 39, p. 3I-36, I974.

KRUGLIANSKAS, I. Ensino da gestão ambiental em escolas de administração de empresas: a experiência da FEA-USP. In: ENCONTRO NACIONAL DE GESTÃO EMPRESARIAL E MEIO AMBIENTE, I993, São Paulo. Anais... São Paulo: FEA-USP, Eaesp-FGV, I993.

MARÔCO, J. Análise de equações estruturais: fundamentos teóricos, software e aplicações. Pêro Pinheiro: Report Number, 20I0. 374 p.

MOORMAN, C.; MINER, A. S. The convergence of planning and execution: improvisation in new product development. Journal of Marketing, v. 62, n. 3, p. I-20, I998.

PAYNE, P. Environmemtal education and curriculum theory. The Journal of Environmental Education, v. 35, n. I, p. I-I2, 2006.

PINHEIRO, L.; MONTEIRO, D.; PEÑALOZA, V.; MACHADO, D. Educação ambiental: um instrumento de diagnóstico para a inclusão da temática de sustentabilidade em instituições de ensino superior. In: SEMINÁRIOS EM ADMINISTRAÇÃO (SEMEAD), I3., 20ıo, São Paulo. Anais... São Paulo: USP, 2OIO.

PORTER, M. E.; LINDE, C. V. D. Green and competitive: ending the stalemate. Harvard Business Review, v. 73, n. 5, p. I20-134, I995.

RAMOS, R. R. Experiência do cliente no ponto de venda varejista. 2009. I43 f. Dissertação (Mestrado em Administração)-Centro de Estudos Sociais Aplicados, Universidade Estadual do Ceará, Fortaleza, 2009 .

RAYKOV, T.; MARCOULIDES, G. A. A first course is structural equation modeling. 2. ed. New York: Psychology Press, 2006. 238 p.

SORDI, M. R. L. Responsabilidade social no ensino superior. Revista da Associação Brasileira de Mantenedores do Ensino Superior (Abmes), Brasília, ano 23, n. 34, p. 29-40, abr. 2005.

STRIFE, S. Reflecting on environmental education: where is our place in the Green Movement? The Journal of Environmental Education, v. 4I, n. 3, p. I79-I9I, 2010.

WARE, J. Standards for validating health measures: definition and content. Journal of Chronic Diseases, v. 40, p. 473-480, I987. 